\title{
SISTEM MONITORING BUDIDAYA IKAN LELE BERBASIS INTERNET OF THINGS MENGGUNAKAN RASPBERRY PI
}

\author{
Erfan Rohadi ${ }^{1}$, Dodik Widya Adhitama ${ }^{2}$, Ekojono ${ }^{3}$, Rosa Andrie Asmara ${ }^{4}$, Rudy Ariyanto ${ }^{5}$, Indrazno \\ Siradjuddin $^{6}$, Ferdian Ronilaya ${ }^{7}$, Awan Setiawan ${ }^{8}$ \\ 1,2,3,4,5 Jurusan Teknologi Informasi, Politeknik Negeri Malang, Jl. Soekarno Hatta No. 9, Malang, 65141 \\ 6,7,8 Jurusan Teknik Elektro, Politeknik Negeri Malang, J1. Soekarno Hatta No. 9, Malang, 65141 \\ Email: 1erfanr@polinema.ac.id, 2adhitamadodik7@gmail.com, ${ }^{3}$ ekojono2@polinema.ac.id, \\ ${ }^{4}$ rosa.andrie@polinema.ac.id, ${ }^{5}$ rudy@polinema.ac.id ${ }^{6}$ indrazno@polinema.ac.id, ${ }^{7}$ ferdian@polinema.ac.id, \\ 8 awan.setiawan@polinema.ac.id
}

(Naskah masuk: 15 Oktober 2018, diterima untuk diterbitkan: 12 November 2018)

\begin{abstract}
Abstrak
Internet of Things merupakan perkembangan teknologi berbasis internet masa kini yang memiliki konsep untuk memperluas manfaat yang benda yang tersambung dengan koneksi internet secara terus menerus. Sebagai contoh benda elektronik, salah satunya adalah Raspberry Pi. Teknologi ini memiliki kemampuan memberikan informasi secara otomatis dan real time. Salah satu pemanfaatan perkembangan teknologi ini di bidang perikanan adalah sistem pemantauan air kolam. Pada prakteknya, para pembudidaya ikan lele masih melakukan pemantauan tersebut secara konvensional yaitu dengan cara mendatangi kolam ikan. Hal ini berpengaruh terhadap efisiensi waktu dan keefektifan kerja pembudidayaan ikan. Pada penelitian ini dikembangkan alat yang berfungsi untuk membantu memantau dan mengontrol kualitas air kolam ikan lele berbasis Internet of Things. Piranti yang diperlukan adalah sensor keasaman $(\mathrm{pH})$, sensor suhu dan sebuah relay untuk mengatur aerator oksigen air. Data dari sensor-sensor tersebut direkam oleh Raspberry Pi untuk kemudian diolah menjadi informasi sesuai kebutuhan pengguna melalui perantara internet secara otomatis. Selanjutnya data-data tersebut dapat ditampilkan dengan berbagai macam platform, salah satunya dengan model mobile web. Hasil uji menunjukan bahwa pengembangan teknologi Internet of Things pada sistem ini dapat membantu pembudidaya untuk melakukan pemantauan terhadap kualitas air secara otomatis. Sistem otomasi yang dikembangkan menjanjikan peningkatan keberhasilan dalam pembudidayaan ikan lele.
\end{abstract}

Kata Kunci: Internet of Things, ikan lele, otomasi, sensor, Raspberry Pi.

\section{INTERNET OF THINGS BASED WATER MONITORING SYSTEM FOR CATFISH POND USING RASPBERRY PI}

\begin{abstract}
For recent years, the Internet of Things becomes the topic interest of improvement based on technologies that have the concept of extending the benefits of an object that is connected to an internet constantly. This technology has the ability to provide information automatically and real time. One of expansion in the field of fishery is the water ponds monitoring system. In the fact, the catfish farmers are still doing conventional monitoring by coming to the fish pond. This could affects the efficiency of time and effectiveness of fish cultivation work. In this research, the systems that can monitor and control the quality of catfish water ponds based on the Internet of Things is proposed. The necessary tools are acidity sensor ( $\mathrm{pH})$, temperature sensor and a relay to adjust water oxygen aerator. The data sensors have been recorded by Raspberry Pi that processed into information according to user needs through internet automatically. Furthermore, these data have been displayed with a variety of platforms, one with a mobile web model. The results shows that the system based on Internet of Things technology can monitor the water quality automatically. The automation system promises the productivity of catfish farming.
\end{abstract}

Keywords: Internet of Things, catfish, automation, sensor, Raspberry Pi. 


\section{PENDAhuluan}

Semakin berkembangnya teknologi masa kini muncul inovasi teknologi yang disebut Internet of Things. Internet of Things (IoT) mengacu pada penggunaan sensor, aktuator dan teknologi komunikasi yang ditanamkan ke objek fisik yang memungkinkan objek tersebut untuk dilacak dan dikendalikan melalui jaringan seperti internet. Penggunaan perangkat ini akan melibatkan tiga langkah utama: pengambilan data menggunakan sensor, pengumpulan data melalui jaringan dan pengambilan keputusan berdasarkan analisis data. Pengambilan keputusan ini dapat menghasilkan peningkatan produktivitas proses saat ini. Ini juga akan memungkinkan jenis produk dan layanan baru yang ditawarkan di berbagai bidang aplikasi (Bansal, et al., 2015)

Raspberry Pi adalah komputer single-board yang memiliki daya yang tidak kalah dari computer desktop kelas menengah. Raspberry $\mathrm{Pi}$ termasuk salah satu alat yang paling banyak digunakan untuk proyek tentang Internet of Things karena ukurannya yang kecil, GPIO, Wi-Fi, dan Bluetooth (Permana, 2015)

Ikan lele (Clarias gariepinus) merupakan komoditas unggulan yang saat ini masih terus dikembangkan oleh pemerintah Indonesia untuk meningkatkan produksi pada sektor perikanan. Ikan berkumis keluarga catfish ini merupakan salah satu komoditas perikanan unggulan di Indonesia, khususnya budidaya air tawar (freshwater aquaculture). Direktur Jenderal Pengolahan dan Pemasaran Hasil Perikanan (P2HP) menyebutkan, $60 \%$ produksi perikanan yang memiliki pasar domestik sangat tinggi adalah perikanan air tawar yang termasuk didalamnya ikan Lele. (Dinas Perikanan dan Kelautan Provinsi Jawa Timur, 2014) Berbagai upaya untuk mengembangkan perikanan budidaya terutama sistem intensif hingga kini masih terus dilakukan mengingat sistem ini masih terkendala oleh berbagai masalah diantaranya adalah kualitas air. (Apriyani, 2017). Kualitas air menjadi salah satu faktor dalam keberhasilan budidaya ikan. Suhu, derajat keasaman $(\mathrm{pH})$ air dan kadar oksigen di air adalah salah satu contoh indikator untuk menentukan kualitas air (Muhammad \& Andriyanto, 2013). Pada prakteknya para pembudidaya ikan masih melakukan pengukuran kualitas air secara manual, yaitu dengan mendatangi kolam ikan dan menggunakan alat ukur sederhana. Itu berpengaruh terhadap keefektifan budidaya ikan.

Salah satu contoh penerapan konsep Internet of Things dalam bidang perikanan ialah sistem monitoring air kolam. (Al Qalit, et al., 2017) Sistem ini dapat memantau kondisi air kolam secara otomatis dan real time menggunakan salah satu komputer mini yaitu Raspberry Pi. Dengan pengembangan teknologi Internet of Things pada sistem ini dapat membantu pembudidaya untuk melakukan pemantauan terhadap kualitas air secara otomatis, sehingga dapat meningkatkan tingkat keberhasilan dalam pembudidayaan ikan lele

\section{METODE PENELITIAN}

Penelitian ini dilakukan langkah-langkah sesuai dengan tahapan pada diagram Fishbone seperti dijelaskan gambar 1

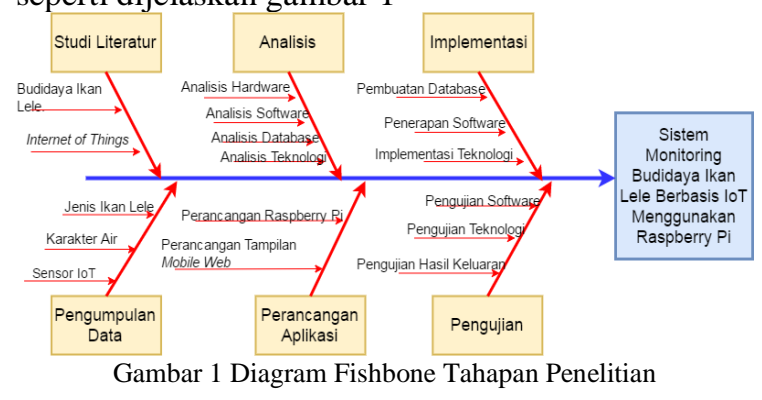

\subsection{Perancangan Perangkat Keras}

Perancangan perangkat keras dibuat dalam bentuk blok diagram sistem yang terdiri dari susunan alat dan sistem secara umum. Pada gambar dijelaskan blok diagram sistem secara umum

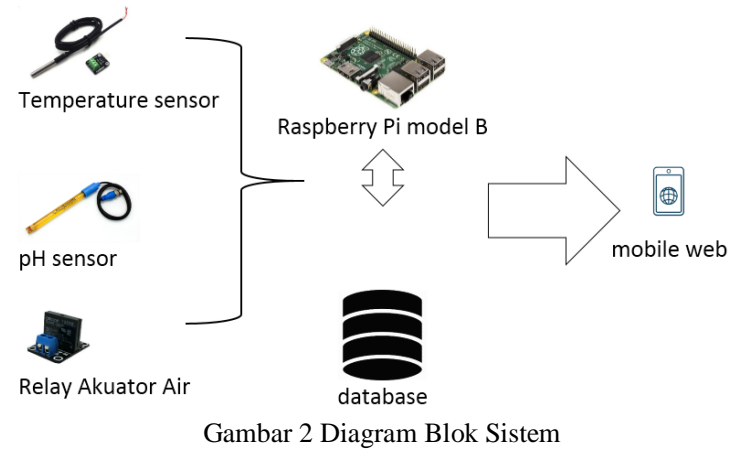

Dalam penelitian ini, dibuat desain arsitektur sistem seperti pada gambar. Raspberry Pi menerima hasil bacaan dari 2 buah sensor yaitu sensor suhu, sensor $\mathrm{pH}$. Kemudian disimpan di Raspberry Pi untuk diolah dengan database pengolahan air kolam ikan lele. Setelah itu Raspberry Pi mengatur waktu yang tepat sesuai database untuk menyalakan dan mematikan relay yang terhubung ke akuator air untuk mengatur kadar oksigen di air. Pada alat ini juga memiliki kemampuan untuk menganalisa jika terjadi eror pada sensor yang dipakai, salah satunya dengan mengambil data bacaan sensor terakhir. Selanjutnya semua hasil data ditampilkan dalam mobile web yang bisa diakses dari smartphone yang terhubung jaringan nirkabel.

\subsection{Perancangan Perangkat Lunak}

Ketika system dijalankan, pertama sistem akan melakukan inisialisasi terhadap nilai dari sensor menjadi nol dan mengatur timer pada posisi off, lalu memuat data pengolahan air. 


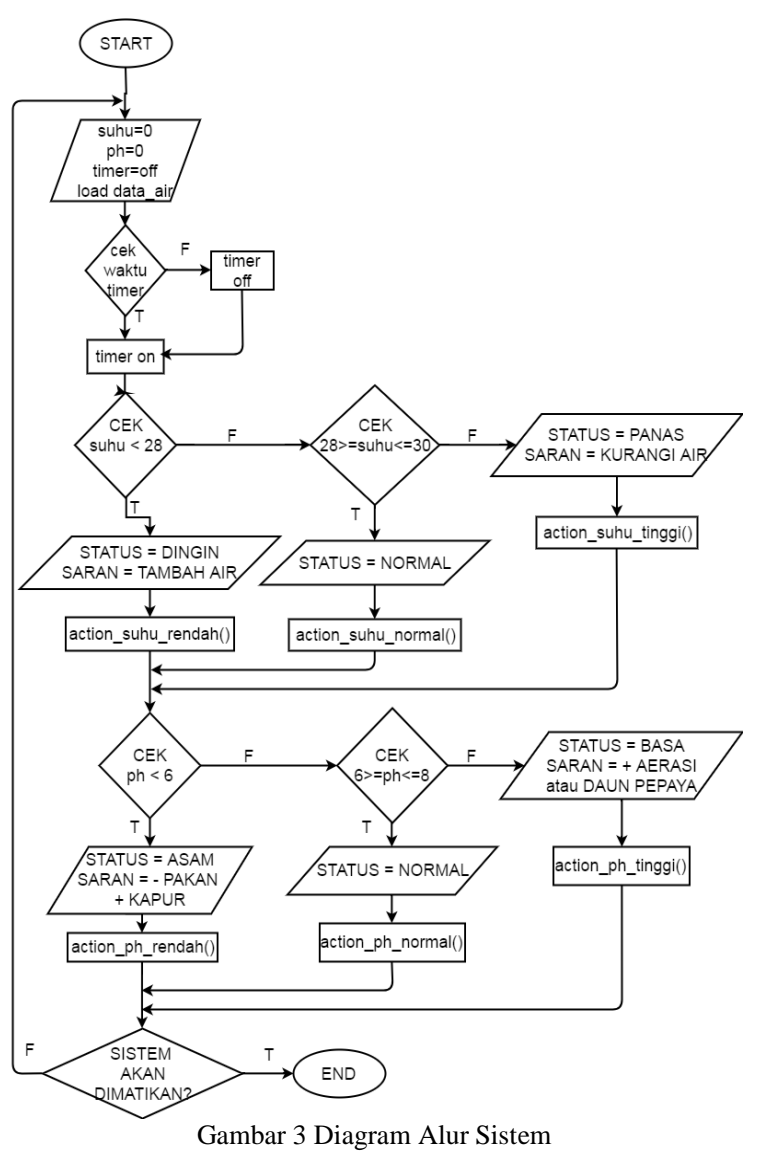

Selanjutnya system akan melakukan pembacaan dari status timer selanjutnya melakukan pengecekan apakah waktu timer susah sesuai dengan data. Setelah itu sistem melakukan pembacaan dari sensor suhu, untuk kemudian dicocokan dengan data air apakah sesuai dengan parameter jangkauan suhu ideal yaitu antara $28-30^{\circ}$ Celcius, jika tidak sesuai, maka akan tampil status dan saran pengolahan air diikuti aksi untuk mengontrol kondisi suhu, lalu berlanjut ke pembacaan sensor ph. Sama seperti pembacaan sensor suhu, sistem mengecek apakah hasil pengukuran sesuai dengan jangkauan $\mathrm{pH}$ ideal yaitu antara 6-8 (Apriyani, 2017), jika tidak maka tampil status kolam dan saran diikuti aksi untuk mengkondisikan $\mathrm{pH}$. Proses ini berulang sampai pengecekan status sistem apakah ingin di matikan atau tidak menunjukan true.

\subsection{Perancangan Kolam Ikan Lele}

Desain kolam yang akan dipakai dalam penelitian ini adalah kolam bundar terbuat dari terpal berdiameter 2 meter, tinggi 1,2 meter serta memiliki padat tebar ikan lele sebanyak 3500 ekor $/ \mathrm{m}^{2}$.

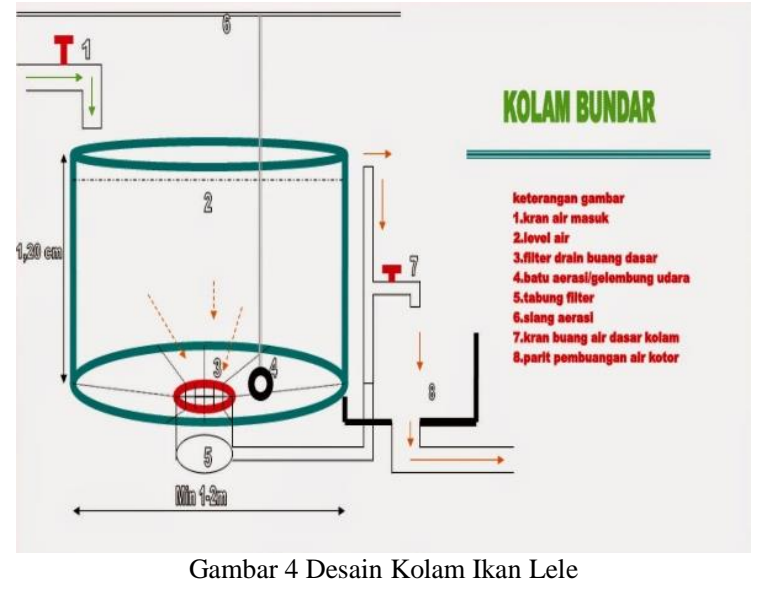

\section{HASIL DAN PEMBAHASAN}

\subsection{Implementasi Sistem}

Pengujian sistem secara keseluruhan dilakukan setelah masing-masing perangkat lunak dan perangkat keras terpasang dengan baik sesuai dengan yang diharapkan pada saat perancangan. Parameter-parameter yang akan di pantau adalah sensor suhu dan sensor derajat keasaman. Data dari sensor tersebut akan di monitoring melalui web browser pada jaringan lokal dan internet, akan diteliti tingkat kecocokannya dengan data pengolahan air dari Dinas Perikanan dan Kelautan Kabupaten Blitar dan beberapa refrensi sebagai patokan pemantauan air kolam. Ketika hasil pengukuran tidak sesuai dengan data tersebut maka di jalankan aksi menyalakan aerator atau mengurangi/menambah tinggi muka air dengan pompa air.

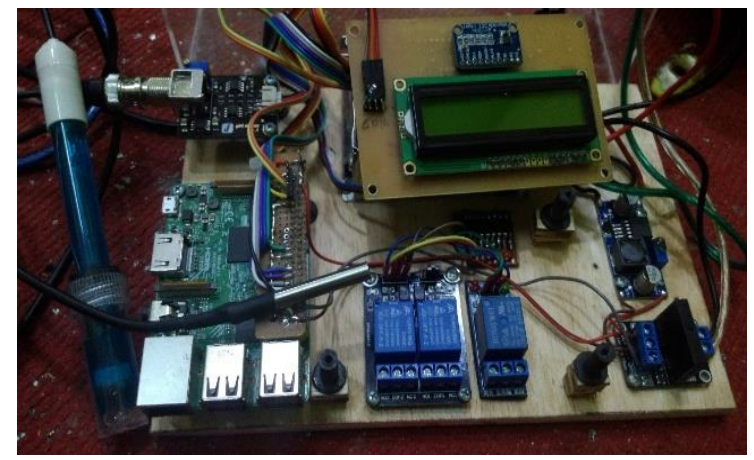

Gambar 5 Implementasi Perangkaian Sensor Suhu dan pH 


\section{Sensor Derajat Keasaman $(\mathrm{pH})$}

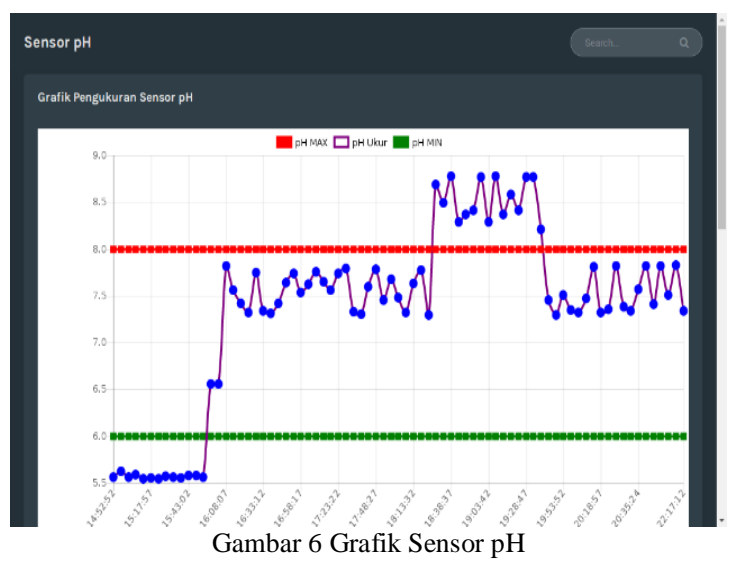

Gambar diatas merupakan grafik pengurukuan sensor pH. Grafik tersebut menujukan kondisi kadar $\mathrm{pH}$ di air kolam selama jangka waktu tertentu. Ketika kadar $\mathrm{pH}$ dalam air dibawah batas, maka akan dilakukan penanganan berupa penyalaan aerator untuk menambah kadar oksigen dalam air, sehingga $\mathrm{pH}$ juga ikut bertambah, sedangkan ketika pH melebihi batas maksimal, sistem akan melakukan pengurangan nyala aerator secara bertahap sampai pada batas pH yang sesuai (Sumarna, 2018)

\section{Sensor Suhu}

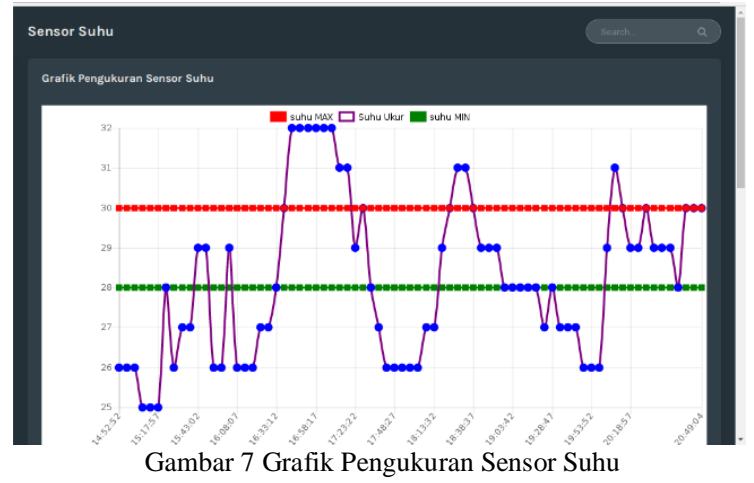

Gambar diatas merupakan grafik pengurukuan sensor suhu. Grafik tersebut menujukan kondisi suhu air kolam selama jangka waktu tertentu. Ketika suhu melebihi atau kurang dari suhu air kolam untuk ikan lele, maka akan dilakukan penanganan tertentu. Ketika suhu dibawah batas, maka sistem akan menyalakan pompa untuk menambah air sampai suhu sesuai dengan batas. Ketika suhu diatas batas maksimum maka penanganan yang dilakukan ialah mengurangi tinggi dari permukaan air. (Al Qalit, et al., 2017)

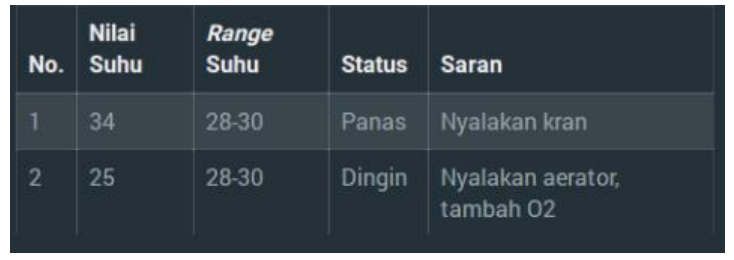

Gambar 8 Hasil Saran Terhadap Pengukuran Suhu

\subsection{Hasil Analisa}

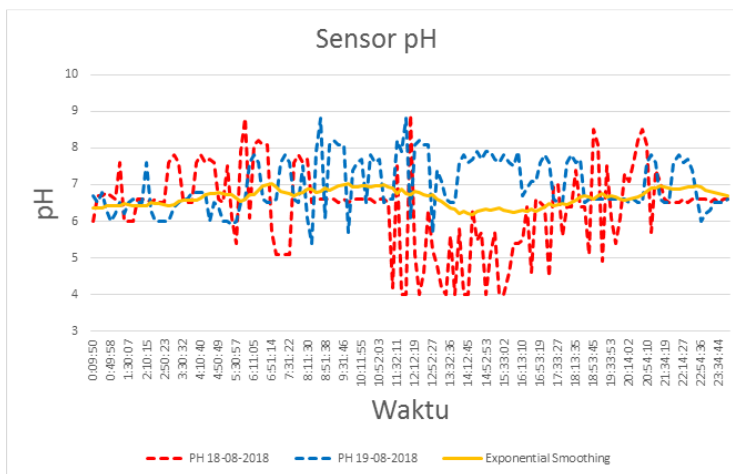

Gambar 9 Hasil analisa pengukuran sensor $\mathrm{pH}$ menggunakan Exponential Smooting

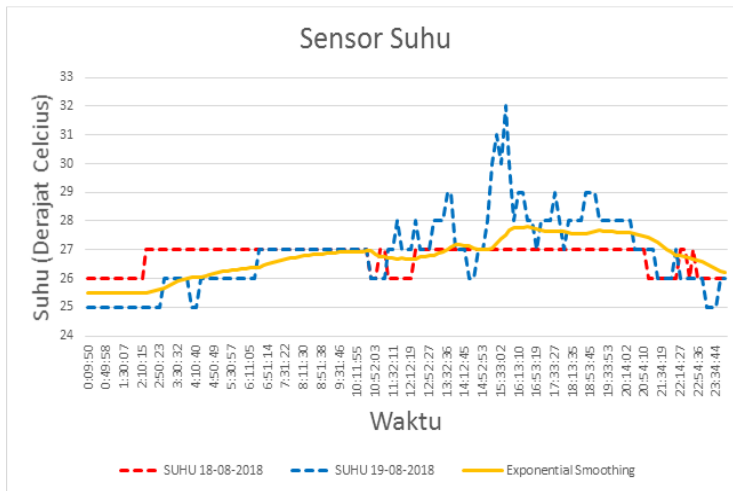

Gambar 10 Hasil analisa pengukuran sensor suhu menggunakan Exponential Smooting

Berdasarkan grafik diatas, dapat diketahui nilai pengukuran sensor suhu dan $\mathrm{pH}$ pada tanggal 18 Agustus (garis merah) dan tanggal 19 Agustus (garis biru). Hasil pengukuran tersebut selanjutnya dianalisa menggunakan metode Exponential Smooting (garis kuning) sehingga di dapat hasil pada pengukuran selama 2 hari suhu dan ph menunjukan tren yang sama.

\section{SIMPULAN}

Kesimpulan yang dapat diambil dari penelitian ini adalah berdasarkan pengujian yang telah dilakukan, pengembangan teknologi Internet of Things pada sistem ini dapat membantu pembudidaya untuk melakukan pemantauan terhadap kualitas air secara otomatis. Selain itu berdasarkan analisa yang telah dilakukan, data pengukuran temperatur dan data tingkat keasaman memiliki trend yang sama. Sistem otomasi yang dikembangkan menjanjikan peningkatan keberhasilan dalam pembudidayaan ikan lele.

\section{DAFTAR PUSTAKA}

AL QALIT, FARDIAN \& RAHMAN, A., 2017.

Rancang Bangun Prototipe Pemantauan Kadar pH 
dan Kontrol Suhu Serta Pemberian Pakan Otomatis pada Budidaya Ikan Lele Sangkuriang Berbasis IoT. KITEKTRO: Jurnal Online Teknik Elektro, pp. 8-

15.

ALDAKA, R. A., 2013. Sistem Otomatisasi

Pengkondisian Suhu, pH, dan Kejernihan Air Kolam Pada Pembudidayaan Ikan Patin. Jurnal Mahasiswa Teknik Elektro Universitas Brawijaya , pp. 1-7.

APRIYANI, I., 2017. Budidaya Ikan Lele Sistem Bioflok. Yogyakarta: Deepublish.

BANSAL, A., YADAV, A. N. \& KULKARNI, A., 2015. Internet of Things, IoT Day Special. San Fransisco: LexInnova.

DINAS PERIKANAN DAN KELAUTAN PROVINSI JAWA TIMUR, 2014. Statistik Perikanan dan Kelautan Provinsi Jawa Timur. Surabaya: Dinas Perikanan dan Kelautan Provinsi Jawa Timur.

MUHAMMAD, W. N. \& ANDRIYANTO, S., 2013. Manajemen Budidaya Ikan Lele (Clarias gariepinus). Media Akuakultur, pp. 63-69.

PERMANA, T. D., 2015. Sistem Monitoring Menggunakan Mini PC Raspberry Pi. Jurnal Komputer dan Informatika .

SUMARNA, C., 2018. Budidaya Lele Sistem Kolam Bundar. Jakarta: Agromedia Pustaka.

YUWONO, T., HAKIM, L., ARDI, I. \& UMAR, 2016. The Application of Internet of Things System for Water Quality Monitoring. Internetworking Indonesia Journal, pp. 49-53. 
Halaman ini sengaja dikosongkan 